\title{
Influence of Process Conditions on Hydroxyapatite Crystallinity Obtained by Direct Crystallization
}

\author{
M.M. Seckler $^{\mathrm{a}, \mathrm{e}_{*}}$, M. Danese $^{\mathrm{a}}$, S. Derenzo $^{\mathrm{a}}$, J.V. Valarelli $^{\mathrm{b}}$, \\ M. Giulietti ${ }^{\mathrm{a}, \mathrm{c}}, \boldsymbol{R}$. Rodríguez-Clemente ${ }^{\mathrm{d}}$ \\ ${ }^{a}$ Instituto de Pesquisas Tecnológicas do Estado de S. Paulo S.A., Divisão de Química, \\ Cidade Universitária, C.P. 0141, 01064-970 São Paulo - S.P., Brazil \\ ${ }^{\mathrm{b}}$ Universidade de São Paulo, Departamento de Petrologia e Mineralogia, \\ Cidade Universitária, 05508-900, São Paulo S.P., Brazil \\ ${ }^{\mathrm{c}}$ Universidade Federal de São Carlos, Departamento de Engenharia Química \\ ${ }^{\mathrm{d}}$ CSIC, Institut de Ciència de Materials, \\ Campus de la UAB, 08193 Bellaterra - Barcelona, Spain \\ ${ }^{e}$ Escola de Engenharia Mauá, \\ 09580-900 São Caetano do Sul - S.P., Brazil \\ *e-mail: seckler@ipt.br
}

Received: March 23, 1998; Revised: March 10, 1999

\begin{abstract}
Crystallization from solutions was applied to produce stoichiometric and crystalline hydroxyapatite (HAP) suitable for use as a biomaterial. This was accomplished by keeping a low supersaturation through the following procedure: semi-continuous operating mode, slow reactant addition rate and addition of a calcium complexing agent. A high temperature $\left(90^{\circ} \mathrm{C}\right)$ and probably carbonate incorporation also favored the formation of a well crystallized material. A qualitative correlation was found between the supersaturation and HAP properties such as crystallinity and particle size.
\end{abstract}

Keywords: hydroxyapatite, bioceramic, biomaterial crystallization precipitation

\section{Introduction}

Synthetic hydroxyapatite (HAP) has been used as a biomaterial for replacement of human hard tissues. For clinical applications where in vivo absorption-recrystallization of the implant is not wanted, HAP should have a high crystallinity, little lattice incorporation of foreign ions (it should be stoichiometric) and little surface adsorption. HAP with these characteristics has been obtained commercially through thermal and hydrothermal methods ${ }^{1}$. The relatively inexpensive crystallization method has found limited use, mainly to produce the raw material for thermal methods ${ }^{1}$, because it usually leads to low crystallinity and non-stoichiometric HAP. The possibilities of the crystallization method are explored here.

HAP crystallization obeys the Ostwald rule of stages ${ }^{2}$, so it is usually formed upon recrystallization of precursor phases such as octacalcium phosphate, dicalcium phosphate dihydrate and amorphous calcium phosphate ${ }^{3}$. Direct HAP formation has been found only for low reactants concentrations (in the $10^{-3} \mathrm{M}$ range and a $\mathrm{pH}$ of 7.4), where the solution was undersaturated or slightly supersaturated with respect to the precursor phase ${ }^{4}$. The HAP obtained through precursor phases is calcium-deficient and requires long maturation times to approach stoichiometry. HAP crystallized directly, on the other hand, is a stoichiometric material with a crystallinity that improves with time. These observations indicate that stoichiometric and crystalline HAP can be produced at low supersaturation values. However, economic considerations dictate that the reactants concentrations should be as large as possible. In order to satisfy these two criteria, a semi-continuous procedure was applied $^{5}$ that consisted of a slow addition of reactants to a crystallizer previously fed with the solvent. The rate of addition of reactants was lower than the rate of crystallization, so the supersaturation was kept low throughout the process and a relatively concentrated suspension resulted (in the $10^{-2} \mathrm{M}$ range). The effect of the supersaturation on the quality of the HAP formed was studied by varying the reactant addition rate, the base concentration, the tempera- 
ture and the $\mathrm{pH}$. Additionally, the effect of other parameters on HAP quality, such as the presence of carbonate, were investigated.

\section{Experimental}

Semi-continuous reactive crystallization of $\mathrm{Ca}_{10}\left(\mathrm{PO}_{4}\right)_{6}(\mathrm{OH})_{2}$ was performed in a mechanically agitated jacketed glass crystallizer with a volume of $1.4 \mathrm{~L}$. The cover held a mercury thermometer, a $\mathrm{pH}$ meter, inlets for the reactants and a condenser. In some experiments a reactor without cover was employed to study the effect of atmospheric $\mathrm{CO}_{2}$ uptake. The reactants used were a $1 \mathrm{M}$ ammonium acetate solution (diluting medium, calcium complexing agent and $\mathrm{pH}$ buffer), a $0.1 \mathrm{M}$ calcium nitrate solution, a $0.0543 \mathrm{M}$ diammonium phosphate solution and a $0.1 \mathrm{M}$ to $7.7 \mathrm{M}$ ammonium hydroxide solution, all prepared with analytical grade chemicals and demineralized water. In experiment 6 technical grade ammonium hydroxide solution was used and did not interfere with the product quality. The counter ions $\mathrm{NH}_{4}{ }^{+}$and $\mathrm{NO}_{3}{ }^{-}$were chosen because they are known to incorporate little in the HAP structure. The first three solutions had their $\mathrm{pH}$ values adjusted to 8.5 - 9.0 just before the start of the experiments to minimize the uptake of atmospheric $\mathrm{CO}_{2}$. The crystallizer was initially fed with $250 \mathrm{~mL}$ of the ammonium acetate solution. At the start of the experiment $400 \mathrm{~g}$ of the calcium nitrate solution and $400 \mathrm{~g}$ of the diammonium phosphate solution were fed to the crystallizer at constant and equal flow rates through two independent inlets. In this way the reactor was fed with the optimum $\mathrm{Ca} / \mathrm{P}$ molar ratio of $1.84^{5}$. After the reactants addition, the suspension was kept under agitation for $4 \mathrm{~h}$. A pH value of 8.50 was kept constant through manual addition of ammonium hydroxide solution. At the end of the run the suspension was vacuum filtered, washed with $2 \mathrm{~L}$ water and $0.5 \mathrm{~L}$ acetone and air dried. The HAP formed was analyzed by X-ray diffraction, infrared spectrometry, X-ray fluorescence spectrometry, chemical analysis for $\mathrm{Ca}$ and $\mathrm{P}$ (gravimetric methods) and scanning electron microscopy. Part of the produced HAP was sintered at $1030{ }^{\circ} \mathrm{C}$ and analyzed by X-ray diffraction. The following parameters were varied: time of reactants addition, temperature, base concentration, contact with atmospheric $\mathrm{CO}_{2}$ and addition of calcium at the start of the experiment (Table 1).

\section{Results}

In experiments 1 and 8 the X-ray diffraction data (Table 2) supported the formation of a mixture of HAP and amorphous calcium phosphate (ACP) in the crystallizer. ACP would form under sufficiently high reactants concentrations ${ }^{6}$ and transform into the observed $\beta$-tricalcium phosphate $(\beta-\mathrm{TCP})$ upon sintering ${ }^{7}$. In experiments 0 and 2 to 7 only crystalline HAP was formed. It is unlikely that an amorphous phase was present, since the materials were stable upon sinterization. The lattice parameters of the HAP from experiment 0 were found to be consistent with a hydroxy-carbonate-apatite with carbonate substituting phosphate ions. A cristallinity index for HAP has been defined based on the width $\beta$ of the peak at $2 \theta=25,8^{\circ}$ at its half-height ${ }^{8}$. In our sintered materials, however, this peak had a low intensity, so $2 \theta=32,9^{\circ}$ was used (Table 2 ). The highest crystallinity was found for experiments 0,6 and 7 .

The infrared spectra has confirmed the presence of $\mathrm{PO}_{4}{ }^{3-}, \mathrm{H}_{2} \mathrm{O}, \mathrm{OH}^{-}$and $\mathrm{CO}_{3}{ }^{2-}$ (Table 2) in all experiments. The carbonate concentration was the highest for experiment 6 (open reactor, high $\mathrm{pH}$ ), followed by experiment 7 (open reactor), in accordance with the chemical equilibria of the system $\mathrm{CO}_{2}-\mathrm{H}_{2} \mathrm{O}$. Surprisingly, the carbonate content in experiment 8 (open reactor, $25^{\circ} \mathrm{C}$ ) was similar to that of experiments 0 to 3 (closed reactor, $90{ }^{\circ} \mathrm{C}$ ). X-ray fluorescence spectra showed the presence of a minor proportion of $\mathrm{Si}$ and traces of the elements $\mathrm{Fe}, \mathrm{Mg}, \mathrm{S}, \mathrm{Sr}$ and $\mathrm{Ti}$. The elements $\mathrm{Cr}, \mathrm{Cu}$ and $\mathrm{Si}$ were detected in some experiments. These elements are likely to derive from impurities in the raw materials. The $\mathrm{Ca} / \mathrm{P}$ molar ratios were within the range 1.65 to 1.81 (Table 2) and can be considered consistent with the value for stoichiometric HAP. The only exception was in experiment 8 , where a ratio of 1.55 was found, consistent with that of ACP $\left(1.45\right.$ to $\left.1.55^{9}\right)$. HAP crystals from experiments $0,2,3$ and 7 appeared as aggregates of acicular primary particles under a scanning electron microscope, as can be seen in Fig. 1. The material from experiments 1, 6 and 8 were aggregates of primary particles too small to be distinguished. The small particles found in experiments 1 and 6 can be attributed to the high supersaturations derived from the high $\mathrm{pH}$ and short reactant addition time. For experiment 6 , the increased carbonate concentration may have contributed to the formation of small particles as well ${ }^{10}$.

Table 1. Experimental conditions. (a) $\mathrm{NH}_{4} \mathrm{OH}$ soln. was technical grade, $\mathrm{pH}=10$; (b) Open reactor; slightly different concentrations of reactants.

\begin{tabular}{lcccc}
\hline Exp. & $\begin{array}{c}\mathrm{NH}_{4} \mathrm{OH} \\
(\mathrm{M})\end{array}$ & $\begin{array}{c}\text { Addition } \\
\text { time }(\mathrm{min})\end{array}$ & $\begin{array}{c}\text { Temperature } \\
\left({ }^{\circ} \mathrm{C}\right)\end{array}$ & Other \\
\hline 0 & 0.1 & 75 & 90 & \\
1 & 7.7 & 30 & 90 & \\
2 & 7.7 & 130 & 90 & \\
3 & 7.7 & 66 & 90 & Base case \\
5 & 1.14 & 122 & 90 & \\
6 & 7.7 & 242 & 90 & (a)(b) \\
7 & 7.7 & 185 & 90 & (b) \\
8 & 7.7 & 196 & 25 & (b) \\
\hline
\end{tabular}


Table 2. Characteristics of the produced materials: main phases identified by X-ray diffraction, cristallinity indexes $1 / \beta$, carbonate content, Ca/P molar ratios and primary particle sizes; (a) large peaks (low $1 / \beta$ ), with superposition; (b) superposition of HAP and $\beta$-TCP peak; (c),+++ and +++ indicate increasing concentrations; (d) HAP is present in a small amount.

\begin{tabular}{lccccccc}
\hline Exp. & $\begin{array}{c}\text { Main Phases } \\
25-90{ }^{\circ} \mathrm{C}\end{array}$ & $\begin{array}{c}\text { Main phases } \\
1030{ }^{\circ} \mathrm{C}\end{array}$ & $1 / \beta 25-90{ }^{\circ} \mathrm{C}$ & $1 / \beta 1030{ }^{\circ} \mathrm{C}$ & $\mathrm{CO}_{3}{ }^{2-}(\mathrm{c})$ & $\mathrm{Ca} / \mathrm{P} \mathrm{mol} / \mathrm{mol}$ & Particle size $\mu \mathrm{m}$ \\
\hline 0 & HAP & HAP & 4.2 & 4.8 & + & 1.65 & 2.5 \\
1 & HAP & HAP, $\beta-\mathrm{TCP}$ & $(\mathrm{a})$ & 4.0 & + & 1.70 & sub-micron \\
2 & HAP & HAP & 3.8 & 4.5 & + & 1.75 & 1.6 \\
3 & HAP & HAP & 3.8 & 4.8 & + & 1.74 & 3.0 \\
5 & HAP & HAP & 3.6 & 5.0 & + & 1.76 & 2.3 \\
6 & HAP & HAP & 4.5 & 5.0 & +++ & 1.81 & sub-micron \\
7 & HAP & HAP & 4.3 & 5.0 & + & 1.69 & 1.9 \\
8 & Amorphous & $\beta-T C P$, HAP (d) & (a) & (b) & + & 1.55 & sub-micron \\
\hline
\end{tabular}

\section{Discussion}

The effect of process parameters on the HAP quality are discussed.

\subsection{Reagents addition time}

Addition times of $60 \mathrm{~min}$ or longer resulted in a well crystallized HAP (experiments 2 and 3 in Table 2). However, the addition time of $30 \mathrm{~min}$ resulted in a mixture of HAP and ACP (experiment 1 in Table 2). For the latter case it is likely that the rate of addition of reactants was higher than the rate of their consumption due to HAP crystallization. Therefore the concentrations of calcium and phosphate ions in the solution built up during the addition period and eventually the solution became supersaturated with respect to ACP, which then formed preferentially. In experiment 6 , where the addition time was the longest ( $240 \mathrm{~min}$ ), the crystallinity index was also the highest. Although this result cannot be attributed exclusively to the addition time (in experiment 6 large amounts of carbonate were present), it suggests ways to further improve the crystallinity.

\subsection{Temperature}

The main phase formed at room temperature was ACP (experiment 8), with minor amounts of HAP, whereas at $90^{\circ} \mathrm{C}$ (experiment 6) HAP crystallized. This behavior cannot be explained from the supersaturations in these experiments, since the solubility of HAP is higher at low temperatures ${ }^{11}$.

\section{3. $\mathrm{NH}_{4} \mathrm{OH}$ concentration}

The materials produced in experiments 0 and 3 are similar, except for a higher cristallinity when a diluted base was used. The resulting low base concentration near the reactor inlet and dilution of the reacting medium favor a

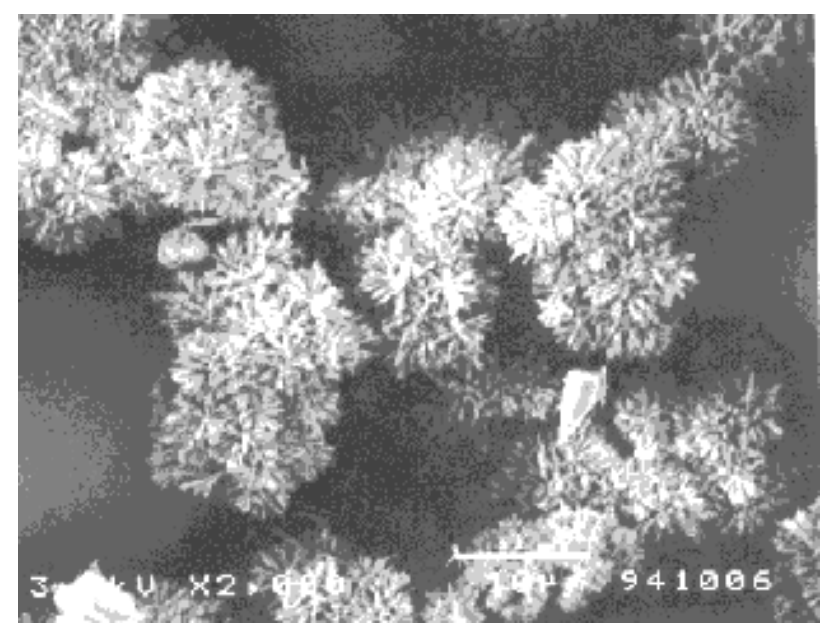

Figure 1. Scanning electron microscopy of HAP from experiment 0.

decrease in supersaturation and therefore the high crystallinity observed.

\section{4. $p H$ and carbonate ions}

HAP with the highest crystallinity of all experiments and with the primary particles in the submicron range was formed at a high $\mathrm{pH}$ (a value of 10) and a high carbonate incorporation (experiment 6 ). Therefore the crystallization method allows the production of particles in the super- and submicron ranges.

\section{Conclusions}

Near-stoichiometric and well crystallized hydroxyapatite was obtained by means of a semi-continuous procedure. Changes in crystallinity and particle size due to varying reagent addition rate, base concentration and $\mathrm{pH}$ were consistent with the corresponding changes in the supersatu- 
ration. Crystallinity and particle size were also strongly affected by the temperature and carbonate incorporation.

\section{Acknowledgments}

The authors are grateful to MCT/FINEP- Financiadora de Estudos e Projetos do Ministério de Ciência e Tecnologia, Brazil - and CYTED - Programa Iberoamericano de Ciencia y Tecnologia para el Desarollo, proj. VIII.6, Spain - for the financial support.

\section{References}

1. Jarcho, M. Clinical Orthopedics and Related Res., n. 187, p. 259, 1981.

2. Kemenade, M.J.J.M. van; Bruyn, P.L. de J. Colloid Interf. Sci., n.118 (2), p. 564, 1987.

3. Nancollas, G.H. et al. Anat. Rec., n. 224(2), p. 234, 1989.

4. Boskey, A.L.; Posner, A.S. J. Phys. Chem., n. 77(19), p. $2313,1976$.
5. Moreno, E.C.; Gregory, T.M.; Brown, W.E. J. of Res. of the Nat. Bureau of Standards - A. Physics and Chemistry, n. 72A(6), 1968.

6. Eanes, E.D.; Posner, A.S. Trans. New York Acad. Sci., Meeting of the Division of Biophysics, Nov. 18, 1965.

7. Jarcho, M.; Bolen, C.H.; Thomas, M.B.; Bobick, J.; Kay, J.F.; Doremus, R.H. J. Mat. Sci., n. 11, p.2027, 1976.

8. Eanes, E.D.; Gillesen, I.H.; Posner, A.S. Nature, n. 208, p. 365, 1965.

9. Seckler, M.M. Calcium phosphate precipitation in a fluidized bed, Ph.D. Thesis, Delft University of Technology, p. 184, 1994.

10. Lenharo, S.L.R. Caracterização mineralógica/tecnológica das apatitas de alguns depósitos brasileiros de fosfato, M.Sc. Thesis, University of São Paulo, EPUSP, p. 196, 1994.

11. McDowell, H.; Gregory, T.M.; Brown, W.E. J. of Res. of the Nat. Bureau of Standards - A. Physics and Chemistry, n. 81A(2 and 3), p. 273, 1977. 